\title{
Urban Streamflow Impact Assessment (USIA): A novel approach for protecting urbanising waterways and providing the justification for integrated water management
}

\author{
Stephanie Kermode ${ }^{a, b}$, Geoff Vietz ${ }^{c}$, Carl Tippler ${ }^{\mathrm{d}, \mathrm{e}}$, Kathryn Russell ${ }^{f}$, Tim Fletcher $^{\mathrm{f}}$, \\ Marlène van der Sterrang ${ }^{g}$, Phillip Birtles ${ }^{a}$ and Michael Dean ${ }^{\mathrm{h}}$ \\ aSydney Water, Sydney, Australia; bSchool of Earth \& Environmental Science, University of \\ Wollongong, Wollongong, Australia; 'Streamology Pty Ltd, Bright, Australia; ${ }^{\mathrm{d} C T E n v i r o n m e n t a l ~ P t y ~}$ \\ Ltd, Wagga Wagga, Australia; e Department of Earth and Environmental Sciences, Macquarie

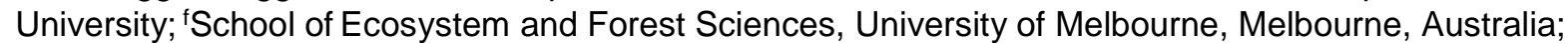

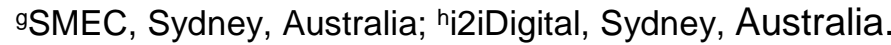

\section{Abstract}

As urban population expand globally, the associated increase in urban land cover directly impacts the social and environmental amenity of natural assets, including waterways. The primary driver of urban waterway degradation is altered hydrology - from stormwater runoff, and where present, wastewater treatment plant discharge. Whilst the impacts of pollutants are relatively well-regulated via public policy, a gap remains for the management of flow regime modification.

The Urban Streamflow Impact Assessment (USIA) was developed to fill this management and planning knowledge gap. The approach begins with the identification of waterway values (social, ecological and geomorphic) then explicitly links these values to streamflow characteristics using hydraulic and hydrologic metrics.

USIA was applied to a case study in Western Sydney and demonstrated the loss of values associated with 'business-as-usual' approaches to stormwater and wastewater management. Conventional stormwater management approaches do not remove enough excess flow to meet reasonable outcomes for the waterway. This excess runoff is increasingly seen as a resource and opportunity for improving water security and liveability.

USIA is consistent with regulatory frameworks and can be applied across developing and established urban catchments to provide explicit input to planning controls. The approach is appropriate at multiple scales, informing urban planning from a broad strategic level through to detailed design. By linking social and ecological values with geomorphic and flow requirements, the approach enables an understanding of which management approaches could allow desirable waterway outcomes to be met.

\section{INTRODUCTION}

Urban development is placing growing pressure on waterways in Australia and around the world. This in turn reduces the social amenity of riverine assets for urban populations. Stormwater runoff from streets, roofs and other impervious surfaces in the urban landscape is typically discharged directly to streams, adversely affecting water quality, as well as increasing the frequency of higher streamflow volumes and flow peaks. Impacts to streams may also be exacerbated by licensed discharges from wastewater treatment plants (WWTP). At the same time, there are increasing expectations that water managers and regulators will play a greater role in supporting environmental management and providing more natural amenities to the community they serve.

The 'urban stream syndrome' is used to describe environmental problems caused by an increase in the volume of urban streamflow, and an increased frequency of small to medium high-energy surges of stormwater (Booth and Jackson, 1997, Walsh et al., 2005). These flow events cause increased disturbance of the channel bed and bank, decreased habitat, reduced native macrophytes, reduced organic matter, increased weed invasion and reduced water quality (Vietz et al., 2014, Tippler et al., 
2014) as illustrated in Figure 1. These changes negatively impact stream-dependent ecosystems including flora and fauna, and the social values streams provide to the community (Birtles et al., 2013).
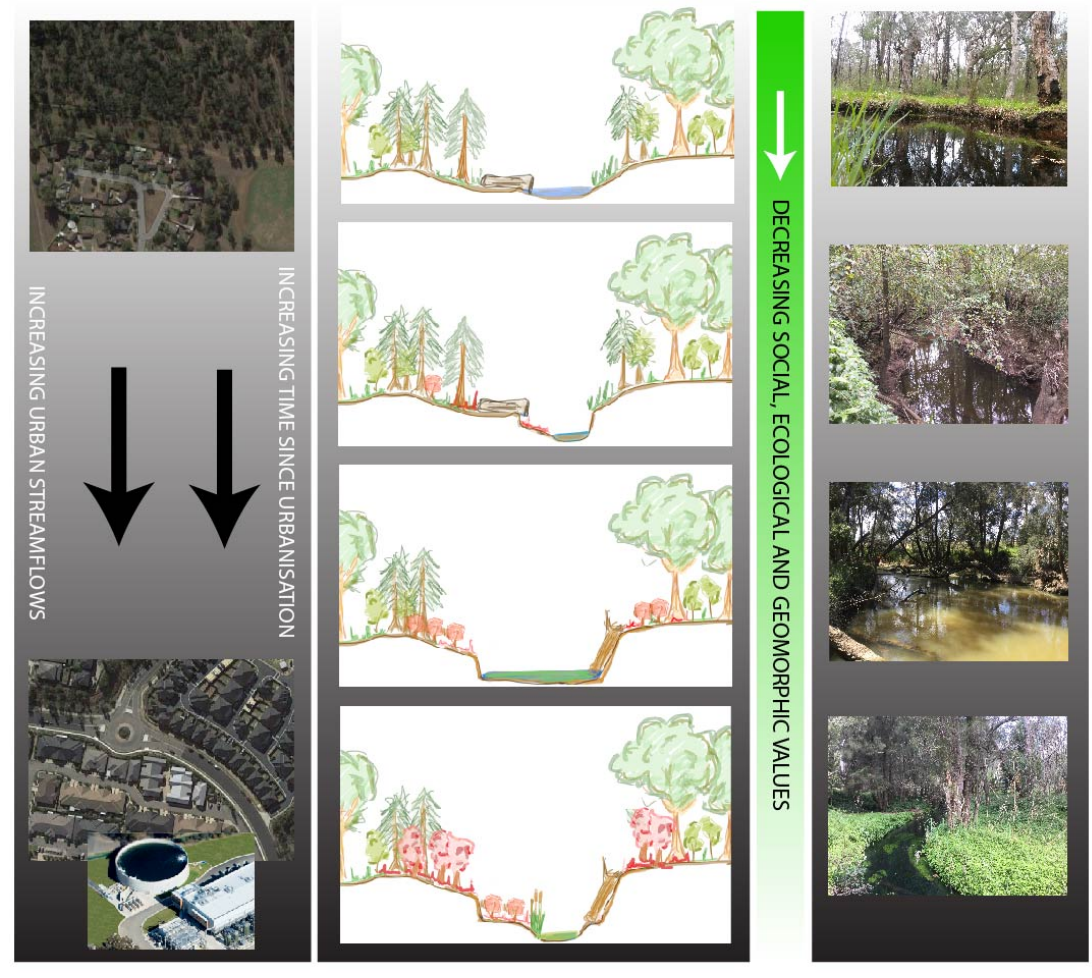

Figure 1. Streamflow and channel changes under urban development including increased channel incision (deepening and widening), decreases in native vegetation (green) and increases in exotic vegetation (red) for increased levels of urbanisation, or time since urbanisation.

Despite extensive research and increasing recognition worldwide of the importance of, and opportunities for, addressing the source of the problem rather than the symptoms (Ball et al. 2016, Bledsoe et al., 2012, Gurnell et al., 2007, Vietz et al., 2016a, Fletcher et al., 2014), there is no formal approach for identifying the impact of streamflow on stream values to inform urban planning and design. Simultaneously to the understanding that urbanisation leads to an excess flow in urban waterways, there is a need to secure additional water supplies globally due to rapidly growing populations and uncertainty around rainfall and climate into the future.

This paper describes the development and application of a new approach termed 'Urban Streamflow Impact Assessment' (USIA) which assesses the role of streamflow in degrading waterways in urban catchments and identifies risks for planning scenarios. USIA has been applied to a case study in the Wianamatta-South Creek catchment in Western Sydney, which is undergoing significant rates of urbanisation with considerable potential to impact on waterway physical form and condition (Kermode et al. 2016). This paper demonstrates how using such an approach can be consistent with existing and emerging regulatory settings and support broader objectives, including integrated water management.

\section{THE 'URBAN STREAMFLOW IMPACT ASSESSMENT' (USIA) APPROACH}

USIA was developed to assess the impacts of altered streamflow on social, ecological and geomorphic values of streams in urban catchments (Figure 2). Values may be specifically defined as important species or ecological communities, social activities or landscape features, which are linked to wider community aspirations and ecosystem services. Stream values are either: a) present and could be lost due to altered urban streamflow; or b) not present but could be returned or added with appropriate streamflow management.

USIA features three stages: 
Stage 1: identification of stream values, delineation of (sub)catchments, selection of assessment reaches, and data review.

Stage 2: development of hydrologic scenarios, hydraulic models, and geomorphic and ecological assessments.

Stage 3: a workshop leading to sub catchment specific social, ecological and geomorphic values and flow metrics, resulting in a compliance and risk assessment evaluating loss of waterway values against increased streamflow resulting from development scenarios.

The main output of these stages is a risk assessment 'traffic light' matrix. The matrix explicitly considers both likelihood (of changes to ecologically relevant parts of the flow regime) and consequence (what values are lost).

The application of USIA to the Wianamatta-South Creek catchment incorporates the socio-ecological system framework proposed by SMCMA (2012) and Birtles et al. (2013) to inform infrastructure planning and decision making. The process of identifying stream values links ecological, social and geomorphic features to environmental factors that may influence the long-term viability of the identified value, if catchment conditions change. These links also provide a critical link to planning instruments, regulation and legislation.

\subsection{Stage 1: establish context and identify values}

The first stage of USIA is to develop an understanding of the catchment context and stream values, including historical, current and potential (desired) values (CTEnvironmental 2016, Tippler et al. 2016). Values are identified by considering: a) what is worth protecting, b) what could be lost, and c) what could be returned or added. Values may be regionally or locally specific, as well as being dependent on the social and economic context. This process may identify species or ecological communities, social activities or landscape features as valuable and links these to wider community aspirations and ecosystem services. The values and their identified ecological requirements are used to develop an integrated approach to waterway management.

The process of identifying stream values may include multiple methods which include;

- $\quad$ Literature review (e.g. scientific and grey literature);

- Public survey;

- Expert knowledge and opinion;

- Workshop or panel; and

- Desktop analysis of protected sites and infrastructure (e.g. National Park and Heritage listings).

This stage also includes gaining an understanding of the physical characteristics of the catchment through desktop review and the collection of spatial data required to inform this understanding and underpin modelling undertaken in Stage 2. Whilst the USIA approach is aimed at managing the entire (sub)catchment, the basis for the identification of values and development of flow metrics is the assessment reach. Selection of appropriate assessment reach(es) is an important output of Stage 1, relying on desktop assessments, local knowledge and should include a field inspection. Considerations should include the location of flow inputs, the condition of stream ecology, and access. It may be appropriate to delineate smaller sub-catchments if a single representative reach is unavailable to represent the wider catchment. 


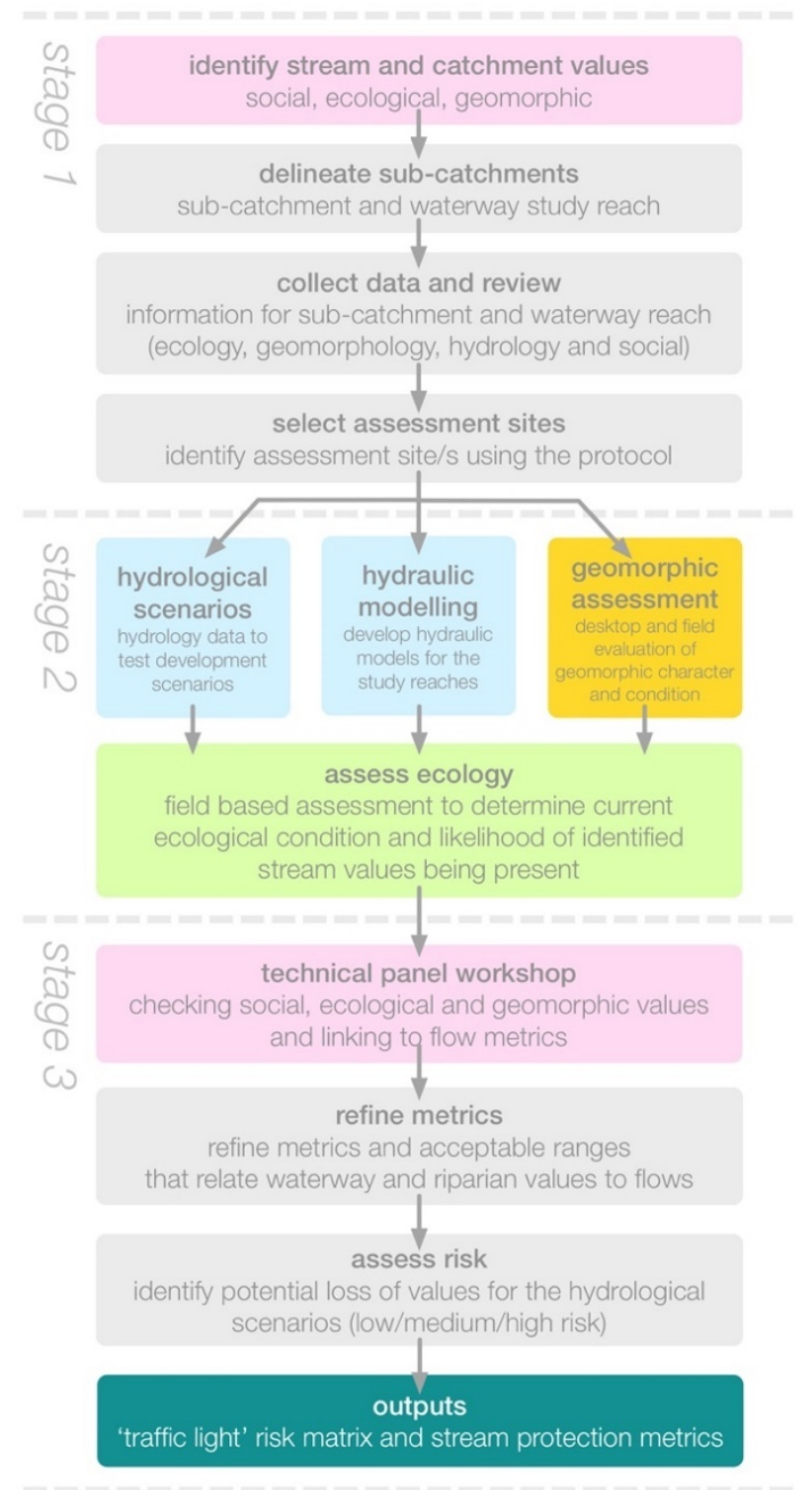

Figure 2. Outline of the Urban Streamflow Impact Assessment (USIA).

\subsection{Stage 2: detailed assessment of study reach}

Stage 2 develops the detailed assessment of the selected study reach. It includes both the modelling (hydrology and hydraulics) and field assessment (geomorphology and ecology) components of the USIA. The hydrologic assessment quantifies how much runoff (and treated effluent where applicable) is delivered to the stream in different scenarios. Flow time-series should ideally be 20 years or longer, and synthetic series should be developed from hydrologic models. We used Australian Rainfall and Runoff methods (Ball et al., 2016). The model should use a sub-daily timestep (maximum one hour); must be able to replicate key parts of the flow regime, including zero flows, low flows, pulse flows and overbank flows; and should be suitably calibrated and validated. Future scenarios need to capture the effects of:

- Impervious surfaces leading to increased runoff volume and frequency;

- Typical flood protection and Water Sensitive Urban Design (WSUD) arrangements reducing peak flows and/or volumes;

- Wastewater treatment plant (WWTP) effluent; and

- Stormwater and/or WWTP reuse strategies. 
Hydraulic modelling is required to link streamflow to physical characteristics of the waterway and floodplain. Hydraulic models convert streamflow to velocity, shear stress and depth, enabling streamflow metrics such as floodplain inundation and bed disturbance to be assessed. A 2D or 3D model is required at a sufficiently fine resolution to undertake analyses such as determining bankfull flow, flow at which bed sediment is mobilised, and typical in-channel and overbank hydraulic conditions at different flow rates. It is important to note that this is not explicitly a flood model, and existing flood models (which are typically built and calibrated to simulate larger flows and may lack sufficient detail for in-channel conditions) should be assessed as to whether they are suitable for this purpose. The hydraulic modelling should simulate a range of steady-state flows (at least 7-10) ranging from in-channel moderate flows up to flows greater than overbank (i.e. median flow, $2 \times$ median flow, 3 $x$ median flow, 2 EY, 1 EY, 50\% AEP, 20\% AEP, 10\% AEP and 5\% AEP).

Despite the increasing recognition of the role geomorphology plays in contributing to healthy and functioning waterways, the availability of data and robust investigations on waterway geomorphology is generally much poorer than for other attributes (e.g. plants, fish). There is also a lack of 'standard techniques' in geomorphic assessment. As such, an experienced geomorphologist who can interpret the character, attributes, condition and trajectory of an urban waterway is required to undertake this assessment. The geomorphic assessment should draw upon all sources of data and information available, and should include:

- Desktop literature review;

- Field assessment; and

- $\quad$ Determination of thresholds of bed mobilization using the Shields parameter (Shields, 1936).

The ecological component of the field assessment is a vital stage which aims to quantify the current condition of the ecological values identified by Stage 1. Depending on the stream values, this may include assessment of a combination of riparian and floodplain vegetation, fauna survey and water quality. Accompanying the field assessment is an intensive literature review and statistical analysis of available data sets to determine hydraulic thresholds when the onset of habitat degradation or species loss occurs. For example, this may require interrogation of regional flora assessment data sets to determine how particular vegetation communities respond to increased flooding arising from an urbanised catchment condition.

To forecast impacts to ecological systems, the combination of field survey (including water quality analysis), data interrogation, literature review and expert opinion is required. Literature relating to the impacts to particular taxa or communities may be sparse or absent. Therefore, biotic or abiotic factors known to be critical to the viability of taxa or communities may be used as surrogates to extrapolate predicted impacts to identified stream values. An example of this is the use of minimum shear stress or velocity required to mobilise sediment or organic matter. These physical responses can provide surrogates for predicting degradation or loss of macroinvertebrate communities as critical habitat or food resources are modified.

\subsection{Stage 3: assess streamflow impacts on values}

Stage 3 articulates the links between the values identified in Stage 1 and the condition assessments and modelling undertaken in Stage 2. It thus enables the determination of management metrics and the analysis of development scenarios and alternate management approaches.

In Stage 3, each value (activity/icon in Figure 3) is linked to a diverse set of flow-related metrics. These values may be human activities (e.g. recreation, aesthetic enjoyment) or biotic icons (particular species or communities). These are then linked to the streamflow, channel or floodplain attributes (ecosystem services) that support them. They may be ecological e.g. specific habitat; physical, e.g. bed/bank stability; or focused on amenity, e.g. clear sight to the waterway. These attributes are linked to streamflow metrics that can be used to quantify changes in the flow regime and associated impacts to the ecosystem services of the stream and floodplain.

The acceptable ranges of deviation of these metrics from baseline conditions and predicted impacts to stream values are refined through a technical panel workshop. Urban development scenarios can include a range of current and future development types, such as business-as-usual, the application of WSUD and the role of WWTPs. Representative flow hydrographs are produced for each development scenario using the hydrologic model. 


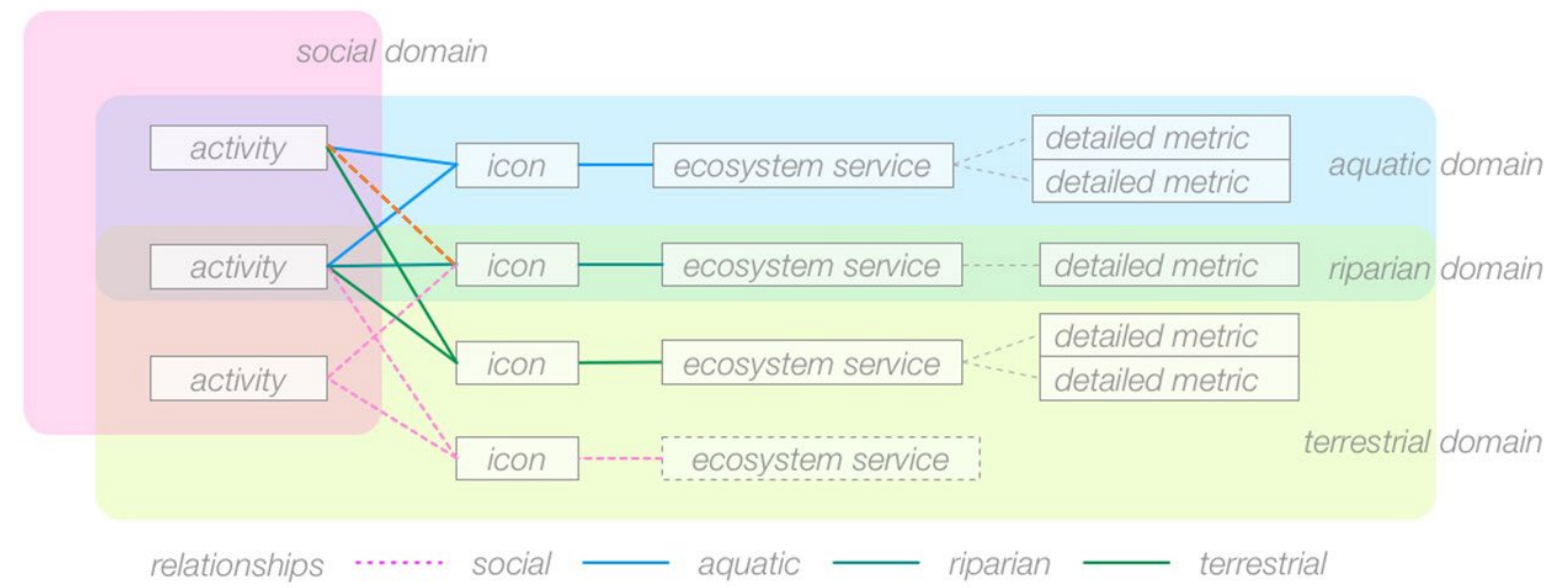

Figure 3. Simplified schema showing colour coding and links for detailed schemas. For this study, iconic species or communities are those with intrinsic links to the human population and have active community groups participating in activities (e.g. fishing, bird watching) directly linked to the species or communities.

Flow metrics reduce the complex flow regime to a range of generalised, ecologically relevant flow types. Flow types range from events that characterise zero flows, to overbank flows that inundate the floodplain (Figure 4). Flow metrics must be quantifiable (i.e. a change in the frequency, duration or magnitude must be measurable under different flow scenarios). Specific flow metrics for this initial application of USIA were selected from a comprehensive review of over 1,000 possible metrics and are those that are specifically relevant to urban settings (Duncan et al., 2014). It should be noted that the flow metrics derived for this proof of concept were selected as appropriate to the catchment used as a case study for developing the assessment approach. The technical panel applying the USIA may add or remove flow metrics, with consideration of those that may best apply to the assessment site.

Nine streamflow metrics relevant to urban settings (and that can be linked to social, ecological or geomorphic values) were selected for application of the method at the case study sites:

1. Annual flow volume;

2. Mean duration of zero flow periods;

3. Total duration of zero flow periods;

4. Baseflow index (ratio of baseflow to total flow volume);

5. Frequency of freshes (flows $>3$ times median flow);

6. Total duration of freshes (flows $>3$ times median flow);

7. Total duration of flows above channel erosion threshold;

8. Frequency of floodplain engagement flows; and

9. Total duration of floodplain engagement flows.

The method uses a range of data, tools and an expert panel to identify the specific thresholds of change from baseline conditions representing risk to desired stream values. For example, geomorphic assessment based on field-identified bed and bank sediments provides input to two-dimensional hydraulic modelling to assess erosion thresholds which informs the sediment mobilisation metric. The deviation of streamflow from baseline conditions for these metrics, under urban development scenarios, is displayed using a 'traffic light' matrix. This highlights the level of risk and values impacted.

The outputs developed by USIA can be applied to assess service options, such as management of stormwater flow regime and WWTP flows or applied to predict positive changes to stream values which may be generated by urban stream restoration projects. The method was originally developed for the Wianamatta-South Creek catchment, Sydney, and the application to one of the case studies, Lowes Creek, is briefly outlined in this paper. Lowes Creek was selected due to planned urban development, and its potential for incorporating a WWTP. 


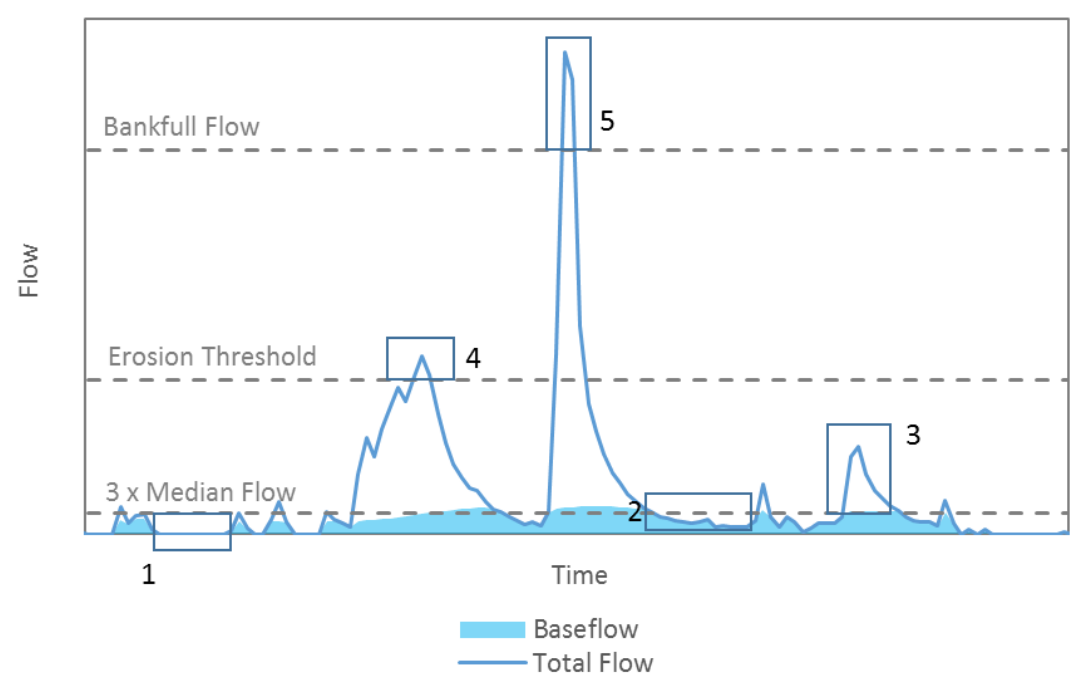

Figure 4. Examples of flow types that can be linked to flow metrics for characterising the impact of streamflow from urban catchments. 1 - zero flow, 2 - baseflow, 3 - freshes, 4 - bed mobilisation flow, 5 - overbank flow.

\section{A SYDNEY CASE STUDY}

Rapid growth is planned in Western Sydney over the coming decades. A large portion of this urbanisation will occur in the Wianamatta-South Creek catchment which is ephemeral in upstream areas and includes rare natural features such as chain-of-ponds. Sydney Water and NSW Government agencies need to plan for essential infrastructure to support delivery of their vision for the region. It is in this context that the USIA framework and these case studies were developed, to establish requirements for urban development to protect or enhance flow-related values connected to the stream.

For Wianamatta-South Creek, stream values were previously identified by Sydney Water and labelled 'Iconic species of South Creek catchment' (Birtles et al 2015, CTENVRONMENTAL, 2016). Each of the nominated 'Iconic species' has specific ecological and environmental requirements, including fluvial habitats, to maintain viable populations across the catchment, and is explicitly linked to a range of social activities valued by the community (Tippler et al, 2016).

The application of USIA to Lowes Creek demonstrated how social, ecological and geomorphic values can be linked to streamflow, and the risks to loss of values under urban development scenarios (Figure 5). The main output of scenario compliance identifies the risk of not meeting acceptable deviations from the adopted baseline conditions (Table 1).

As this was a proof of concept rather than a formal assessment, modelling used available hydrology at a daily time step, which is not recommended during more robust applications. We recommend a maximum of an hourly model timestep, although for small areas higher temporal resolution may be required to capture flow varaiblity. Nonetheless, the assessment provided indications of the relative risk levels of different scenarios. In order to reduce the risk to waterway ecosystems to a low level, the unmitigated 2050 annual flow volume needs to be reduced by more than $50 \%$. The simulated WSUD scenario falls short of this, with only around a $20 \%$ decrease in annual flow volume. Even when high retention WSUD was applied to the model, erosion metrics still identified as high risk, indicating the level of retention needs to be even greater if stream form and function are to be preserved. When the effect of WWTP effluent is considered for Lowes Creek, the volume reduction required is even greater, at around $90 \%$. Such reductions are likely to require significant stormwater harvesting and reuse, and near-total wastewater reuse or transfer out of the catchment. It should be noted that current results are skewed by the daily time step of the modelling. Further development and research is continuing to reflect the runoff in more detail, providing potentially more retention and further reductions in volume. 


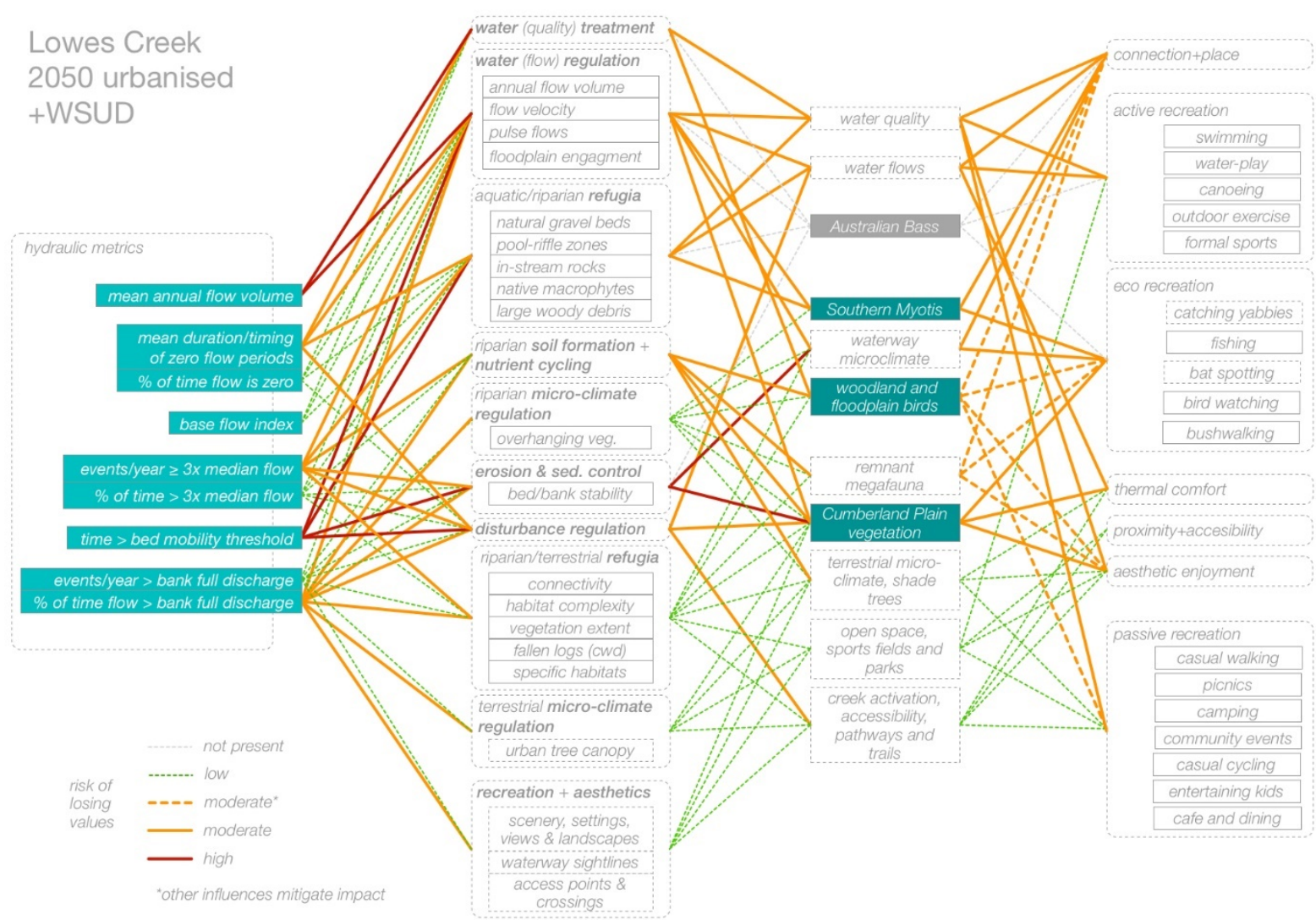

Figure 5. Risks of development to Lowes Creek, Sydney. Schema interpreting links between stream values and flow metrics and risk of full urban development 2050 with maximum WSUD.

Table 1. Scenario compliance assessment of flow metrics for Lowes Creek showing high risk to values (red), medium risk (orange) and low risk (green), with cell values quantified through preliminary modelling in the USIA method.

\begin{tabular}{|c|c|c|c|c|c|c|c|}
\hline \multirow[t]{2}{*}{ Flow type } & \multirow[t]{2}{*}{ Flow metric } & \multirow{2}{*}{$\begin{array}{l}\text { Threshold } \\
\text { value }\end{array}$} & \multicolumn{5}{|c|}{ Scenarios } \\
\hline & & & Baseline & 2050 no WSUD & $\begin{array}{l}2050 \text { high } \\
\text { retention } \\
\text { WSUD }\end{array}$ & $\begin{array}{l}2050 \text { no WSUD + } \\
\text { WWTP }\end{array}$ & $\begin{array}{l}2050 \text { high retention } \\
\text { WSUD + WWTP }\end{array}$ \\
\hline Annual flow & $\begin{array}{l}\text { Mean annual flow } \\
\text { volume }\end{array}$ & & 1,015 & 2,472 & 1,902 & 12,615 & 12,044 \\
\hline Zero flows & $\begin{array}{l}\text { Mean duration of zero } \\
\text { flow periods }\end{array}$ & $0.001 \mathrm{ML} / \mathrm{d}$ & 5.8 & 5.7 & 7.0 & 0 & 0 \\
\hline Zero flows & $\%$ of time flow is zero & $0.001 \mathrm{ML} / \mathrm{d}$ & $58 \%$ & $58 \%$ & $63 \%$ & $0 \%$ & $0 \%$ \\
\hline Baseflow & $\begin{array}{l}\text { Baseflow index } \\
\text { (ratio baseflow/ total } \\
\text { flow) }\end{array}$ & & 0.041 & 0.040 & 0.033 & 0.708 & 0.737 \\
\hline Freshes & $\begin{array}{l}\text { Events/year }>3 x \\
\text { baseline median flow }\end{array}$ & $1.94 \mathrm{ML} / \mathrm{d}$ & 23 & 37 & 31 & exceeded all the time & exceeded all the time \\
\hline Freshes & $\begin{array}{l}\% \text { of time }>3 \times \text { median } \\
\text { flow }\end{array}$ & $1.94 \mathrm{ML} / \mathrm{d}$ & $17 \%$ & $25 \%$ & $20 \%$ & $100 \%$ & $100 \%$ \\
\hline Erosion threshold & $\begin{array}{l}\text { \% of time > } \\
\text { bank/matrix } \\
\text { mobilisation threshold }\end{array}$ & $40 \mathrm{ML} / \mathrm{d}$ & $1.7 \%$ & $4.8 \%$ & $3.6 \%$ & $16.0 \%$ & $14.0 \%$ \\
\hline Erosion threshold & $\begin{array}{l}\% \text { of time }>\text { bed } \\
\text { mobilisation threshold }\end{array}$ & $110 \mathrm{ML} / \mathrm{d}$ & $1.3 \%$ & $3.2 \%$ & $\sim 2.4 \%$ & $5.5 \%$ & $\sim 4.5 \%$ \\
\hline $\begin{array}{l}\text { Floodplain } \\
\text { engagement flows }\end{array}$ & $\begin{array}{l}\text { Events/year > bankfull } \\
\text { discharge }\end{array}$ & $680 \mathrm{ML} / \mathrm{d}$ & 0.5 & 0.5 & $\sim 0.5$ & 0.6 & $\sim 0.6$ \\
\hline $\begin{array}{l}\text { Floodplain } \\
\text { engagement flows }\end{array}$ & $\begin{array}{l}\text { \% of time flow > } \\
\text { bankfull discharge }\end{array}$ & $680 \mathrm{ML} / \mathrm{d}$ & $0.21 \%$ & $0.21 \%$ & $\sim 0.15 \%$ & $0.25 \%$ & $\sim 0.19 \%$ \\
\hline $\begin{array}{l}\text { Ecological values } \\
\text { impacted }\end{array}$ & & & & & Southern & is, Cumberland Plain Veg & etation \\
\hline $\begin{array}{l}\text { Social value } \\
\text { impacted }\end{array}$ & & & & $\begin{array}{l}\text { Connection to plac } \\
\text { comfort, aesthetic }\end{array}$ & $\begin{array}{l}\text { active recree } \\
\text { and enjoymer }\end{array}$ & $\begin{array}{l}\text { eco-recreation, thermal } \\
\text { ssive recreation }\end{array}$ & $\begin{array}{l}\text { Connection to place, } \\
\text { active/passive/eco- } \\
\text { recreation, thermal comfort, } \\
\text { aesthetics and enjoyment, } \\
\text { proximity and accessibility }\end{array}$ \\
\hline
\end{tabular}


USIA demonstrated that under future urban development scenarios, annual flow volumes and the duration above the erosion threshold posed a high risk to ecological values such as microbats (Southern Myotis) and the condition of woodland vegetation (Cumberland Plain woodland) and a range of social values associated with the waterway (Figure 6). Loss or degradation of iconic biota and assemblages leads to reduced opportunity for, and quality of, valued human activities dependent on these natural elements. The compounding effect of stormwater runoff and WWTP effluent discharges increased the deviation of all metrics from their baseline, posing a high risk of loss of all present ecological values, with subsequent impacts on the social values. High retention WSUD applications reduced the extent of loss of such values. Note that the modelling represented volume of excess water retained by extensive WSUD, it did not recommend or represent individual devices.

To achieve reductions in the unmitigated annual flow volume of more than $50 \%$ and protect social and environmental values, significant stormwater harvesting and reuse will be required (see Wong and Engineers Australia, 2006). The key elements are harvesting and use of stormwater and wastewater, through irrigation or the provision of alternative water supplies, or transfer out of the catchment. To achieve appropriate reductions, the level of stormwater control measure application will be ambitious, but numerous options and opportunities are revealing themselves (Vietz and Hawley, 2018). The next phase of our work will more broadly apply the USIA methods and use outputs to inform hydrologic modelling of urban stormwater control opportunities (using Source and MUSIC) to identify practical solutions and the feasibility of such approaches. This will be done at an hourly time step to better reflect the retention of low flows.

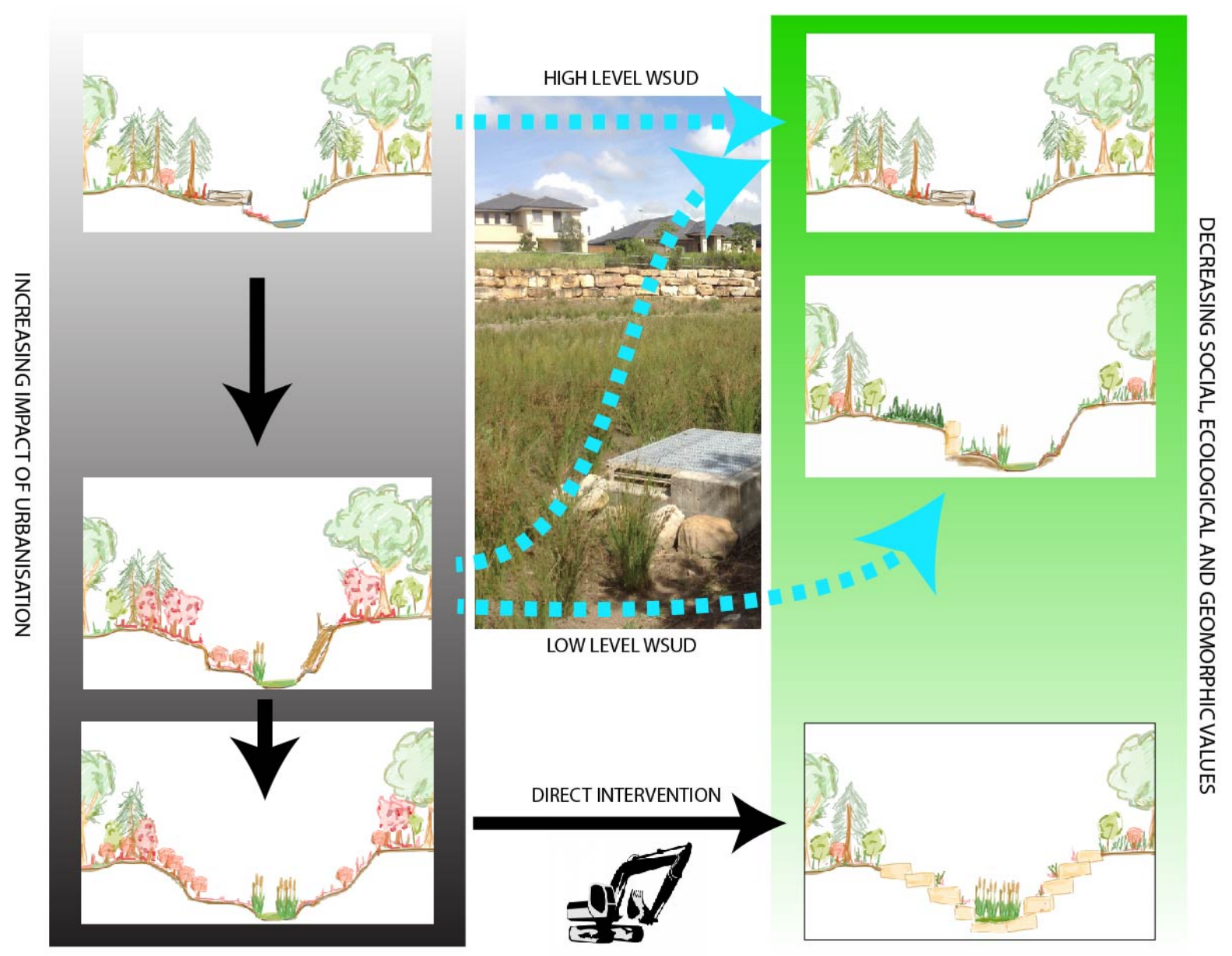

Figure 6. Potential trajectories of adjustment for streams draining urban catchments, with opportunities for returning to a former state, or a novel state, rely on addressing streamflow change through flow controls on stormwater runoff (such as WSUD) and WWTP discharges 


\section{KEY FINDINGS AND OPPORTUNITIES}

This study provides an initial proof of concept for the development and application of the Urban Streamflow Impact Assessment (USIA). Further iterations and refinements are needed to ensure that USIA becomes a robust tool for application; as follows:

- $\quad$ More extensive testing of USIA: The development and testing of USIA was undertaken in two deeply incised channels which will affect their response to urbanisation scenarios. Broader application of USIA to streams with more engaged floodplains will likely attribute greater impact to ecological and social values from catchment urbanisation. The lower portions of Wianamatta-South Creek would be ideal for such testing and may assist in the identification of controls to prevent dramatic end-of-system changes in streamflow. Additionally, the values here are likely to differ from the ephemeral headwater streams of the two case studies.

- Review of urban hydrologic scenario: Further investigations of more ambitious stormwater control methods to address the streamflow volume and pattern objectives identified in this project is required. There is significant and ongoing investigation into the performance of more novel urban typologies more directly integrated with stormwater harvesting and treatment approaches. New permeability performance planning targets and urban forest canopy targets will also challenge the generic urban flow inputs used in stormwater modelling and should be reassessed specifically using localised climate data. USIA or similar tools will provide the information to set targets for the design of these systems. These infrastructure performance targets, combined with USIA outcome targets will work in concert. In short, the urban areas of the future, especially in Western Sydney, are unlikely to pass on as much flow as current models predict.

- $\quad$ Predicting channel change: This initial version of USIA was used to predict impacts to creek values based on changes to flow hydraulics and inundation extent. An additional important factor is understanding the likely scale of creek channel change i.e. channel widening and deepening. The inclusion of this metric will enhance the ability of the framework to predict impacts on riparian vegetation and ecological values which could affect species such as woodland birds and microbats which are reliant upon these areas.

- Improving understanding of the ecological condition of urban creeks receiving wastewater treatment plant (WWTP) discharge: To predict the change in condition of creek attributes such as fish habitat and riparian and floodplain vegetation for the current study, an extensive riparian condition data set was provided by Blacktown City Council. This data enabled prediction of changes in creek attributes and vegetation communities in the urbanisation-based scenarios with a high degree of certainty. It, however, lacked comprehensive data relating to urban creeks that receive WWTP discharges.

- Consistency in analysis: Future development of USIA will benefit from a core data set of the condition of creek floodplain vegetation exposed to WWTP discharges. Expert opinion on acceptable deviation from baseline should also be verified as more data and experience is gained with this method.

- Defining social values: High importance is given to social values in driving desirable physical and ecological attributes for waterways. It was noted by reviewers of this method that further investigation could be made into the role of social drivers, such as how 'open space' or 'creek activation' relates to the supporting attributes provided by waterways.

- Monitoring: Determining the effectiveness of recommendations would be improved through monitoring changes to creeks following catchment development. This could include monitoring of hydrologic (e.g. streamflow gauges), geomorphologic (e.g. channel change from re-survey or bed sediment changes), or ecological (e.g. vegetation or biotic repeat assessments) processes.

Although the focus of USIA is to quantify flow regime management targets in developing areas, its inherent water balance component allows contribution to broader aspects of water related planning, 
notably integrated water management. There is increasing recognition that for our cities to be liveable, resilient and sustainable, a significant change in governance, regulation and development practice is required.

\section{INTEGRATION INTO THE REGULATORY CONTEXT}

To protect urban waterways from damage associated with altered hydrology, scientific assessment frameworks and preventative options must be supported by regulatory frameworks which enforce these requirements. For example, in New South Wales, any development subject to a review of environmental factors or environmental impact statement (Environmental Planning and Assessment Act, 1979) needs to consider the NSW Water Quality and River Flow objectives (DEC, 2004). These objectives in turn follow the ANZECC water quality guidelines and the risk-based assessment approach (ANZECCIARMCANZ, 2000). The understanding of ANZECC by industry has been challenging and to provide more clarity and direction, the Office of Environment and Heritage in partnership with the NSW Environment Protection Authority (2017) developed the effects-based assessment framework which is consistent with the National Water Quality Management Strategy (DAWR, 1994). This risk-based framework sees a transition towards ensuring the community's environmental values underpin strategic land-use planning and waterway objectives. The policy and regulation are intended to balance environmental performance with land-use development in a manner that is sustainable, practical and viable, economically and socially. The approach was initially developed in the Western Sydney context where a 'parkland city' is envisaged by the Greater Sydney Commission (2018), incorporating a blue-green grid to assist with urban cooling and providing amenity to the communities living there.

USIA was developed in accordance with the effects-based assessment framework (Figure 7), as such, it works it concert with existing regulatory and legislative frameworks. While the risk-based framework applies to all aspects of achieving waterway objectives, USIA explicitly focuses on the flow component of waterway health. The implementation of USIA would require a step change in stormwater management above and beyond current targets which commonly focus on reducing pollutant loads from the developed state. Removing a substantial volume of stormwater from the receiving waters will likely go beyond current nutrient removal. However, while flow reduction can meet or exceedtotal load reductions for pollutants, consideration must still be given to concentrations of pollutants entering waterways, and their appropriate management (e.g. DEC, 2006).

Risk-based framework

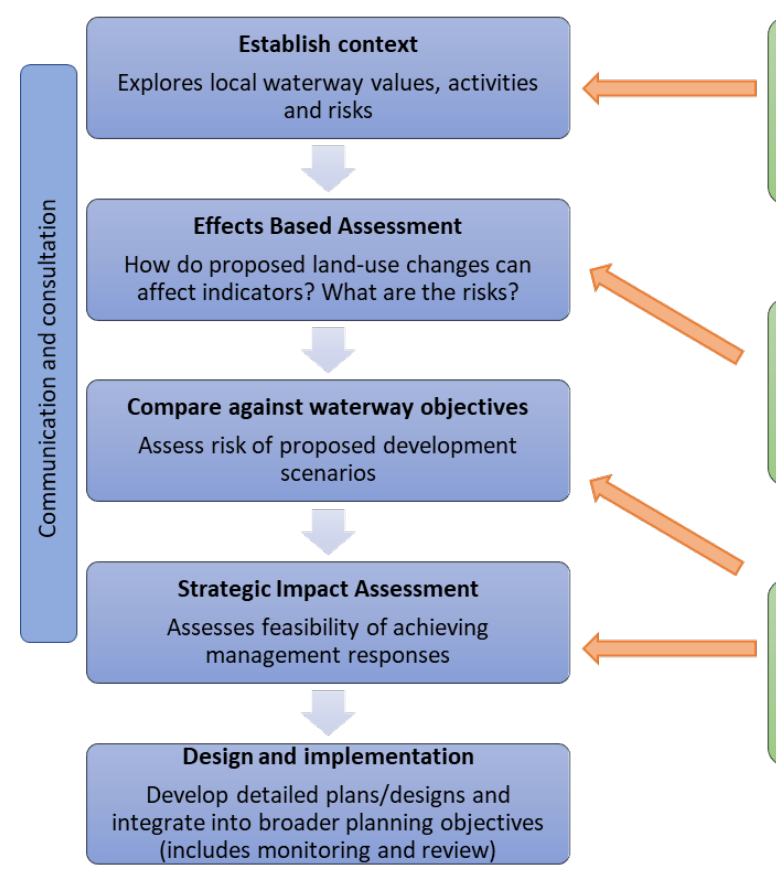

USIA

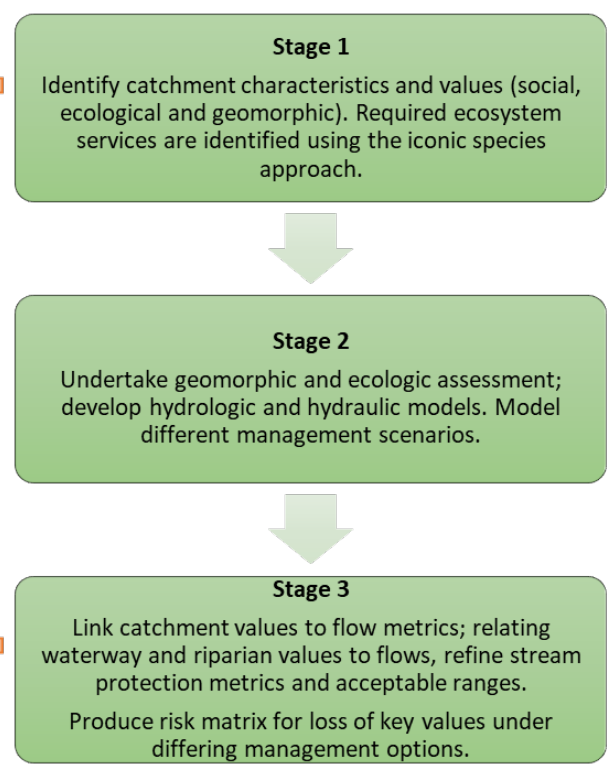

Figure 7. Alignment of USIA with Risk-based Framework (OEH and EPA 2017). 


\section{CONCLUSIONS}

USIA is intended for application wherever increased streamflow associated with urban development threatens the values of receiving streams, including streams in greenfield development areas, or periurban and urban areas where housing density is increasing through infill development. USIA highlights the importance of reducing the overall volume of streamflow in urban catchments, as well as disturbance events, and enables informed value judgements to be made about development scenarios. Options to address these can have wider benefits including additional usable catchment water resources and improved liveability through recreational space provision, watering and cooling. While urban stream degradation is about more than just streamflow (e.g. Vietz et al., 2016b), by controlling flows, it is expected to strategically protect, rehabilitate or maintain the ecological, geomorphic and social values of existing streams in urban environments.

As far as we are aware, USIA is the first practical approach available to link urbanisation to streamflow and subsequently quantify the impacts on the key values, including social and ecological considerations. It is expected that through ongoing application and monitoring, the approach will be refined. The overarching goal is that the application of USIA adequately informs planning and development within the current NSW policy settings. The application of USIA is being further tested in Wianamatta-South Creek, Sydney, followed by potential uptake in the planning and design of cities and suburbs more broadly.

\section{ACKNOWLEDGMENTS}

This project was initiated and funded by Sydney Water. With thanks to lain Fairbairn, Paul De Sa, Shalini Das, Tiffany Chen, Kaushal Kumander, Warda Anwar and anonymous reviewers for their reviews and encouragement. Marlène van der Sterran was employed at Sydney Water for the duration of the project. This paper was presented at the Stormwater Australia 2018 Conference.

\section{REFERENCES}

ANZECC/ARMCANZ (2000). Australian and New Zealand guidelines for fresh and marine water quality. In 'National Water Quality Management Strategy Paper No. 4'. pp. 3.5-1-3.5-10. (Australian and New Zealand Environment and Conservation Council and Agricultural and Resource Management Council of Australia and New Zealand.)

Ball, J. E., Babister, M. K., Nathan, R., Weinmann, P. E., Weeks, W., Retallick, M., and Testoni, I., (2016), Australian Rainfall and Runoff-A Guide to Flood Estimation.

Birtles, P., Hoban, A., Tippler, C., Davies, P.J. \& Wright, I. (2015) Liveability and an Urban Creek: Perspective and dreams of residents who are not yet. $9^{\text {th }}$ International Water Sensitive Urban Design Conference, Sydney.

Birtles P., Hore J., Dean M., Hamilton R., Dahlenburg J. and Moore J. (2013), Creating a Liveable City - The Role of Ecosystem Services. State of Australian Cities Conference, Sydney 2013, Conference proceedings.

Bledsoe, B. P., Stein, E. D., Hawley, R. J., and Booth, D., (2012), Framework and tool for rapid assessment of stream susceptibility to hydromodification, Journal of the American Water Resources Association, 48(4), 788-808.

Booth, D. B., and Jackson, C. R., (1997), Urbanization of aquatic systems: degradation thresholds, stormwater detection, and the limits of mitigation, Journal of the American Water Resources Association 33(5):1077-1090.

CTEnvironmental, (2016), Iconic species of the South Creek catchment, Report for Sydney Water. 
Dela-Cruz, J., Pik. A., and Wearne, P., (2017), Risk-based framework for considering waterway health outcomes in strategic land-use planning decisions, Office of Environment and Heritage and Environment Protection Authority, Sydney.

Department of Agriculture and Water Resources (DAWR), (1994), National Water Quality Management Strategy, http://www.agriculture.gov.au/water/quality/nwqms, accessed 1/8/2018), Australian Government, Canberra.

Department of Environment and Conservation (DEC), (2006), Western Sydney Growth Centres Stormwater Guidance for Precinct Planning, New South Wales Government, Sydney.

Department of Environment and Conservation (DEC), (2004), NSW Water Quality and River Flow Objectives, New South Wales Government, Sydney. https://www.environment.nsw.gov.au/ieo/

Duncan, H.P., Fletcher, T.D., Vietz, G. and Urrutiaguer, M., (2014), The feasibility of maintaining ecologically and geomorphically important elements of the natural flow regime in the context of a superabundance of flow, Melbourne Waterway Research-Practice Partnership Technical Report. 14.5

Environmental Planning and Assessment Act, 1979 (NSW)

Fletcher, T. D., Vietz, G. J., and Walsh, C. J., (2014), Protection of stream ecosystems from urban stormwater runoff; the multiple benefits of an ecohydrological approach, Progress in Physical Geography 38(5):543-555.

Greater Sydney Commission, (2018), Greater Sydney Regiona Plan: A Metropolis of Three Cities, State of New South Wales, Sydney.

Gurnell, A. M., Lee, A., and Souch, C., (2007), Urban rivers: hydrology, geomorphology, ecology and opportunities for change, Geography Compass 1(5):1118-1137.

Hawley, R. J., and Vietz, G. J., 2016. Addressing the urban stream disturbance regime. Freshwater Science, 35(1), 278-292.

Kermode, S., Birtles, P., Vietz, G., Lynch, S., Dixon, J., Tippler, C., and Dean, M., (2016), The expanding role of urban fluvial geomorphology: South Creek, in Vietz, G.J., Flatley, A.J., Rutherfurd, I.D., 31 July - 3 August 2016, Leura, NSW, Australia.

Shields, A., (1936), Anwendung der Aechichkeits-mechanik und der turbuleng forschung aufdir Geschiebewegung' Mitt Preussische. Versuchsanstalt fur Wasserbau and Schiffbau, Berlin.

Sydney Metropolitan Catchment Management Authority (SMCMA), (2012), Sydney Metropolitan CMA 2012 Catchment Action Plan - A Plan for Sydney's Liveability. SMCMA, Parramatta.

Tippler, C., Dean, M., Birtles, P., Davies, P., Belmer, N., and Kermode, S., (2016), Eco-servicing South Creek: A case study from Australia's largest urban growth precincts, in Vietz, G.J., Flatley, A.J., Rutherfurd, I.D., 31 July - 3 August 2016, Leura, NSW, Australia.

Tippler, C., Wright, I.A., Davies, P.J., and Hanlon, A., (2014), The influence of concrete on the geochemical qualities of urban streams, Marine and Freshwater Research 65, 1009-1017.

Vietz, G.J., Sammonds, M.J., Walsh, C.J., Rutherfurd, I. D., and Stewardson, M. J., (2014), Ecologically relevant geomorphic attributes of streams are impaired by even low levels of watershed effective imperviousness, Geomorphology 206: 67-78.

Vietz, G. J., Walsh, C. J., and Fletcher, T. D., (2016a), Urban hydrogeomorphology and the urban stream syndrome: treating the symptoms and causes of geomorphic change, Progress in Physical Geography DOI 10.1177/0309133315605048. 
Vietz, G. J., Rutherfurd, I. D., Fletcher, T. D., and Walsh, C. J., (2016b), Thinking beyond the channel: Challenges and opportunities for stream morphology protection and restoration in urbanizing catchments, Landscape and Urban Planning 145:34-44, DOI 10.1016/j.landurbplan.2015.09.004.

Vietz, G. J., and Hawley, R. J., (2018), Protecting and managing stream morphology in urban catchments, Chapter 12, in Sharma, A., Gardner, T., Begbie, D., Approaches to water sensitive urban design Woodhead Publishing, Elsevier., pp. 626.

Walsh, C. J., Roy, A. H., Feminella, J. W., Cottingham, P. D., Groffman, P. M., Morgan, R. P., (2005), The urban stream syndrome: current knowledge and the search for a cure, J. N. Am. Benthol. Soc. 24(3):706-723.

Wong, T. H. F., Engineers Australia. (2006). Australian runoff quality: a guide to water sensitive urban design. National Committee on Water Engineering. Crows Nest, NSW. 


\section{University Library}

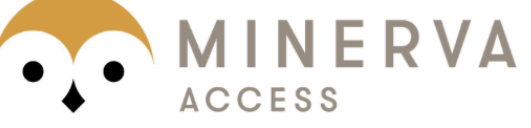

A gateway to Melbourne's research publications

Minerva Access is the Institutional Repository of The University of Melbourne

Author/s:

Kermode, S;Vietz, G;Tippler, C;Russell, K;Fletcher, T;van der Sterran, M;Birtles, P;Dean, M

Title:

Urban Streamflow Impact Assessment (USIA): a novel approach for protecting urbanising waterways and providing the justification for integrated water management

Date:

2020-10-23

\section{Citation:}

Kermode, S., Vietz, G., Tippler, C., Russell, K., Fletcher, T., van der Sterran, M., Birtles, P. \& Dean, M. (2020). Urban Streamflow Impact Assessment (USIA): a novel approach for protecting urbanising waterways and providing the justification for integrated water management. AUSTRALASIAN JOURNAL OF WATER RESOURCES, 25 (2), pp.211-221. https://doi.org/10.1080/13241583.2020.1824330.

Persistent Link:

http://hdl.handle.net/11343/288179 